acute hospitals, contributes most to the prevention of progression of disease even if it is unable to prevent the onset of disease. In practice, so-called preventive medicine contributes very little to the prevention of ill health.

IEUAN DAVIES

Postgraduate Medical Centre,

Raigmore Hospital,
Inverness IV2 3UJ

${ }^{1}$ Davies IJT. Br Med F 1978;i:104-5.

\section{Where have all the nurses gone?}

SIR,-I feel that many of the writers who have so far contributed to the correspondence (9 February, p 406; 16 February, p 486) about "Where have all the nurses gone?" (19 January, p 199) have shown a degree of emotion which is totally inappropriate, and also that doctors are always very anxious to correct the deficiencies in nursing without looking at their own failings. Furthermore, it is impossible to be aware of the work entailed in any job unless one has been the job-holder. A number of erroneous statements have been made by your correspondents, and I would like to correct these.

Firstly, nursing is not a profession in the true sense of the word, and our medical colleagues are frequently the first to ensure that it is not regarded as such. Secondly, it is untrue to say that doctors are no longer asked to give lectures to nurses. They are asked very frequently but often decline the offer. In addition, some of the lectures which are presented are of such poor quality that those who deliver them are not requested to repeat their performances. The "myriads" of nurse tutors to which reference was made in one letter spend a great deal of their time attempting to cajole truculent physicians and surgeons into sharing their knowledge with nursing colleagues. These tutors also spend many hours interpreting those lectures which are incomprehensible to their students.

I would like to state that, contrary to common thought, most nurses find the role of the nursing officer to be ambiguous. I am sad to say, however, that when I attempted to warn one of the consultants with whom I worked in 1966 that the outcome of "Salmon" would not be favourable he accused me of overreacting. With regard to the reduction in working hours, most nurses, again, consider it unnecessary.

Finally, may I ask doctors to consider their attitudes towards nurses, and the pressure of work to which they subject them. If some attention were paid to both of these, not only would relationships improve but more of us might continue to practise the skills in which we were trained.

London SE1 4JF

Pamela M JefFeries

\section{Medical advisory machinery}

SIR,-The debate on medical advisory machinery in the National Health Service promises to be one of the major issues for the Association in 1980. I would remind your readers that the issue was referred to Council after a full debate in the Northern Regional Council last October. I am grateful that the matter has been fully reported in your journal (9 February, p 418). What are the main issues at the present time?
(1) Health authorities have been receiving medical advice which is fragmented, duplicated, and indeed triplicated. Doctors have complained of the tremendous amount of time being spent debating and redebating the same issues in different committees. (2) Health authorities would certainly welcome one channel of professional advice that they could regard as the voice of authority from the profession. (3) The British Medical Association, enjoying great authority within the profession and even greater authority outside it, is singularly well equipped to offer that advice and to provide the necessary advisory machinery. (4) The debate in Council demonstrated that the issue was divisive, but $D$ Ralph Lawrence made the cogent point when he said that "the future of the Association lay in the periphery but the divisions were doing less and less."

The divisions will become more active only if more business is channelled through them, and the taking on of an advisory function no only will strengthen the division but at the same time will boost the membership. True, the divisional structure will have to be so arranged that all crafts are represented therein but this is a minor issue. Non-members will observe the scale and quality of the business being channelled through divisions; they will not only be ready and anxious to join the Association but would also be prepared to play a full and active role in Association affairs.

In the North of England the Association has always had a strong political role. I am well aware that this position does not obtain everywhere, and this may well be reflected in the attitudes of some members of Council. If at the end of the day the local BMA division does not become the sole source of medical advice at the very least its right to be consulted must be written into the new advisory structure.

I hope that this major issue will become a topic of lively debate up and down the country.

LiONEL Kopelowitz

Newcastle upon Tyne NE3 4BP

\section{An effect of inflation}

SIR,-Three years ago I bought my present car for $£ 1740$. Today I was offered $£ 1800$ in part exchange for an identical but new car These now cost $£ 3800$ with delivery charges, number plates, etc.

In many ways, I am fortunate to be offered so good a price, but it does make nonsense of the fact that my accountant has been allowing me $25 \%$ of the remaining value of my car as depreciation each year, on which I am allowed tax relief as I use my car for professional purposes. I will now have to pay back my tax relief, although in practice I need to find $£ 2000$ to get the same car new.

I hope that our negotiators will bear this effect of inflation in mind.

Harlow, Essex CM18 7LU

JOHN TROWELL

\section{Domiciliary visits by consultants}

SIR,-I read with interest the letter from Dr P E Jackson (26 January, p 256) regarding domiciliary visits by consultants, and would like to support the views expressed by him.

Here the communication and discussion with the patients' general practitioners is of the utmost importance in deciding which patients need an immediate hospital admission, as an emergency, and which patients can be seen and assessed by the consultant in his outpatient clinic. There are outpatient clinics once or twice a week in every specialty in the hospital, and in the specialty of rheumatology they are held four or five times a week. In this way much valuable time of the consultant can be saved, which he can devote to the care of his patients, and to teaching, instructing, and supervising the work of the junior medical staff. This also saves considerable money for the National Health Service.

In my view, the only occasion when a consultant wants to do a domiciliary visit is when he wishes to see the patient who is physically too ill to travel in his domestic and social environment to assess the nature of his disability, and his need of the other social services, so as to keep him at home as long as possible to save an acute hospital bed. Such occasions, however, are few and far between.

I know a number of consultants who do not undertake domiciliary visiting of patients, and there are a number of area and regional health authorities who do not insist that they do so.

M A KHAN

Department of Rheumatology and

Rehabilitation,

Royal Northern Hospital,

London N7 6LD

\section{Inner city GPs}

SIR,-Although I am sympathetic to Dr G E Crawford's suggestions (16 February, p 500) for attracting general practitioners to our declining inner cities, my experience as chairman of the area health authority's planning team for primary care in Liverpool is that the barriers to their implementation are by no means always as local as he implies. While I would not underestimate the importance of local authority co-operation in the provision of suitable premises, their financing has been considerably hindered by the Government's effective withdrawal of the annual capital allocation for primary care schemes, with the result that the situation has altered from one of postive discrimination to one of open competition with secondary care and other capital schemes in the regional programme.

In the current financial climate the Department of Health and Social Security, must pay more than lip service to developing the community sector if any real shift of resources is to occur. Major investment is a prerequisite to achieving revenue savings through community care, but neither bridging finance ${ }^{1}$ nor a revenue investment programme, ${ }^{2}$ one of which would be required to effect this, has ever been forthcoming.

A number of incentives to recruitment, like the special payments to older practitioners making way for younger ones which $\mathrm{Dr}$ Crawford suggests, have been put forward in recent times. These have included salaried appointments; limited list sizes; catchment areas and populations; a compulsory retirement age for inner city GPs; the attachment of trainees to elderly single-handed practitioners, with a guarantee that they will "inherit" the practice on the incumbent's retirement; weighting of capitation payments for "highdependency" groups such as the handicapped; financial incentives (on the lines of the type D allowance) linked to inner city practices; and 
short-term contracts (not subject to the control of the Medical Practices Committee) for vocationally trained GPs entering inner city practices.

I recently sent this list to the Chief Medical Officer, in order to discover which of these we might implement locally, but was disappointed to be told that the answer was none, because "the FPC does not have the sort of discrimination you have in mind to alter locally the GPs' detailed terms of service or the scheme of fees and allowances under which the practitioner is paid. It is a question of settling arrangements nationally which are flexible enough to enable them to be adapted to provide local solutions in all circumstances." The General Medical Services Committee and DHSS report on under-doctored areas ${ }^{3}$ would appear to offer little hope for any change in this situation.

The 1974 reorganisation of the NHS was intended to integrate primary and secondary care and to achieve minimum national standards via the new systems for planning and resource allocation. If the Government really puts patients first then surely it is time to grant health authorities the opportunity for positive discrimination in the development of general practice in inner cities, and to integrate the planning and resource allocation systems, so that central priorities have a real chance of becoming local realities.

Alex Scott-Samuel

Liverpool Area Health Authority

Liverpool L3 9NG

${ }^{1}$ Mersey Regional Health Authority. Report of a committee of inquiry. January 1978.

(19.8

Anonymous. Br Med 7 1979;ii:1380-3.

SIR,-In his letter (9 February, p 407) Dr J A Jewell refers to the idea of an initial practice allowance for inner city areas. As he says, this has been proposed by the Working Party on Under-doctored Areas. Before this suggestion becomes accepted uncritically as "a good thing" we should examine it more closely.

The "legendary aging singlehanded practitioners" to whom Dr Jewell refers have smal lists of patients. The income from their practices may be adequate for elderly doctors with few expenses. For a young man with a family who has to live in London a list of 1000 or 1200 patients is simply not large enough. To augment his income for a few years by a special allowance assumes that he will eventually increase his list to, say, 2500; but this can be done only at the expense of neighbouring practices.

The population of inner London has been falling steadily for the past 30 years. Many general practitioners have kept going only because the Executive Council and the family practitioner committees have dispersed these small lists or transferred the patients to adjacent practices. This policy could be changed, of course, but such a change would have to take heed of the interests of the doctors who are giving general medical services at present. The situation is quite different from that in the New Towns, where at first there are no doctors and a growing population. To introduce a salaried service on a piecemeal basis side by side with independent contractors would lead, in a few years, to everyone trying to survive with small and dwindling lists.

\section{Closing the gap between GPs and} hospitals

SIR,-While I agree that the profession should maintain as close a working relationship as possible between the GP and his hospitalbased colleagues, Dr J Crane's proposals to close the gap (9 February, p 423) are based on false assumptions about the nature of the general practitioner's role.

A GP is, by definition, a generalist and an individual. Primary care medicine in this country functions on this assumption and eliminates the need for a patient to make a self-diagnosis, a prerequisite where there is direct access to a specialist. Furthermore, most patients prefer to relate to an individual doctor rather than a "group." The specialist has evolved as a feasible solution to the ever-continuing explosive advancement of medical knowledge. It is assumed that it is better for a practitioner to deal knowledgeably with a few diseases than inadequately with all diseases. There can be no argument about this if we are considering the understanding of specific diseases.

Primary care medicine deals with the breakdown of health in all its aspects. Specific diseases are only one aspect of this. Indeed, it is the preoccupation with specific diseases (an inevitable consequence of medical education based largely on hospital experience) which often leads to difficulties in effecting good general practice, something which needs to concern itself as much with the philosophical aspects of ill health as it does with compartmentalising individual illnesses. To say that clinical observation is only a preliminary to choosing an appropriate diagnostic technique is to be blinded by technology and obsessed by a need to make definitive diagnoses. The prime concern for the GP should be in helping the patient to achieve overall improvement in health, restricting diagnostic techniques and specialist involvement merely as a means to this end. In most instances the GP is able to base his conclusions on observation alone.

It has also been observation of illness in the community rather than advances in "high technology" which has increased understanding of the genesis of ill health and its relation to the style of living of the patient and his family. To assume, as Dr Crane has done, that "the rapidly changing face of twentieth century medicine" is a phenomenon confined solely to hospital experience is to imply that practice of medicine in the community cannot advance itself without direct reference to hospital-based medicine. Ideally, the two should run in parallel, both maintaining their own degree of excellence. Each should understand what the other is trying to achieve without losing sight of their individual roles. If the specialist moves too near the community and the GP becomes too preoccupied with inpatient care and specialisation there is a real danger that neither group will achieve its full potential.

Bath BA2 4BY

R L RoLLS

\section{A4 records}

SIR,-Dr F J Borchardt (9 February, p 407) draws attention to the growing requirement for A4 records. In 1976 the annual conference of local medical committees approved a motion from the Berkshire Local Medical Committee "that this conference accepts that the A4 type of record folder is an improved method of record keeping with significant benefits in patient care." However, the 1975 conference was adamant that before any general introduction of this system the Department of Health and Social Security would have to give a firm undertaking that any consequent alterations to equipment and premises arising therefrom would be financed by the Department. The latter issue has not yet been resolved and the Department has been extremely reluctant to supply A4 records.

The GMSC recently agreed that the Department should now be urged to provide these records for doctors who request them in practices where suitable accommodation already exists, and the Royal Commission on the National Health Service recommended that they should be introduced as a matter of priority. Because of this complicated situation many doctors are reluctant to part with their A4 folders and certainly they should not be sent to colleagues who are unwilling to use them. I feel therefore that the best way to progress is by pressure on the Department at a national and individual practice level for a liberal supply of these records.

The interesting suggestion for amending the FP4 to include an "A4 acceptable box" may not be well received as it would entail an alteration to a national medical card and might only be necessary for a period of a few years until the problems are resolved. It might, however, be worth individual colleagues themselves entering prominently "A4 acceptable" on the FP4s to see if this evokes any response through the family practitioner committees.

It is an appropriate time to move forward on this issue as doctors who use the A4 system, either in part or in whole, find it of considerable benefit, and trainees-who often have the unenviable task of searching through the standard record envelopes for informationare strongly in favour of them.

Reading, Berks RG3 3AN

GORDON TAYLOR

\section{Medical students and the HJSC}

SIR,-We are writing from the annual general meeting of the Medic's Working Party of the National Union of Students to register our disquiet over the proposed mechanism for election of two medical students to represent student views on the Hospital Junior Staff Committee (HJSC).

The Medics' Working Party is part of the Health Students' Section of the NUS, which represents all health students. The working party represents medics within the union, and is elected from our AGM. Although not all medical schools are members of the NUS they can all be involved in the Medic's Working Party and have full voting rights.

In the $B M \mathcal{F}$ (20 October, $p$ 1014) it was stated that an election was to be held for two student representatives to sit on the HJSC, and that only associate members of the BMA would be able to vote. We believe that this is totally undemocratic; only a proportion of medical students would be able to vote, and thus the students could hardly be representative of medics as a whole. The situation is particularly ludicrous since the HJSC is meant to be an "independent" committee and doctors involved in it do not have to be BMA members. 